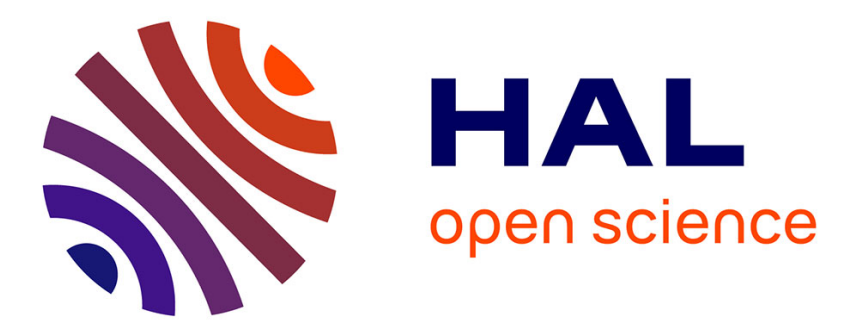

\title{
Comparative Study between kinetic and thermodynamic calculation of composition in SF6 Plasmas
}

\author{
Vincent Rat, Pascal André, Jacques Aubreton, Marie-Françoise Elchinger, \\ Pierre Fauchais, André Lefort
}

\section{- To cite this version:}

Vincent Rat, Pascal André, Jacques Aubreton, Marie-Françoise Elchinger, Pierre Fauchais, et al.. Comparative Study between kinetic and thermodynamic calculation of composition in SF6 Plasmas. Sixth European Conference on Thermal Plasma Processes Strasbourg, France May 30 - June 3, 2001, 2001, France. pp.411-418. hal-00019951

\section{HAL Id: hal-00019951 https://hal.science/hal-00019951}

Submitted on 2 Mar 2006

HAL is a multi-disciplinary open access archive for the deposit and dissemination of scientific research documents, whether they are published or not. The documents may come from teaching and research institutions in France or abroad, or from public or private research centers.
L'archive ouverte pluridisciplinaire HAL, est destinée au dépôt et à la diffusion de documents scientifiques de niveau recherche, publiés ou non, émanant des établissements d'enseignement et de recherche français ou étrangers, des laboratoires publics ou privés. 

CALCULATION OF COMPOSITION IN SF 6 PLASMAS

\author{
V. Rat ${ }^{1}$, P. André2, J. Aubreton', M.F. Elchinger', P. Fauchais', A. Lefort ${ }^{2}$ \\ ${ }^{\prime}$ SPCTS University of Limoges, 123 av. A. Thomas, 87060 Limoges cedex, France \\ ${ }^{2}$ LAEPT Blaise Pascal University, 24 av. des Landais, 63177 Aubière cedex, France
}

\begin{abstract}
For an $\mathrm{SF}_{6}$ plasma at atmospheric pressure the compositions calculated in chemical equilibrium, in the multi-temperature model and using kinetics (33 reactions involving 18 species) are compared. The ratio of the electron temperature $T_{e}$ to that of heavy species $T_{h}$ was calculated as a function of electron density and an intermediate temperature $T^{*}$ between $T_{e}$ and $T_{h}$ was introduced to cope with the relationship $k_{f}\left(T^{*}\right) / k_{r}\left(T^{*}\right)=K_{x}\left(T^{*}\right)$ where $k_{f}$ and $k_{r}$ are the reaction rate coefficients (forward and reverse) and $K_{x}$ the equilibrium constant. The main difference between equilibrium and kinetic calculations lies in the densities of $\mathrm{S}^{+}, \mathrm{S}_{2}^{+}, \mathrm{SF}^{+}, \mathrm{F}^{-}$ and $\mathrm{S}^{-}$species between 2000 and $6000 \mathrm{~K}$. The multi-temperature method gives results very different from those of the kinetic calculations even when neglecting the charge loss reactions. This is in contrast to what happens with $\mathrm{H}_{2}$ or $\mathrm{N}_{2}$.
\end{abstract}

Key words: SF6 plasma composition, multi-temperature

\title{
1-Introduction
}

A plasma, whatever might be its composition, must be maintained by conservation of its constituents as well as an input of energy (a current due to the existence of an electric field in a thermal plasma). The balance of energy gain (heating) and loss (cooling) of the heavy particles and electrons in the plasma is time and location dependent and is very seldom in perfect equilibrium. In order to determine the plasma flow and the resulting momentum, heat and mass transfers to a material to be treated the degree of non-equilibrium must be determined. It allows to calculate the plasma composition, its transport properties and then the flow properties.

Many works have been devoted to the non-equilibrium problems using either multitemperature mass action law, equivalent to Gibbs free energy minimization [1-5] including multi-temperature partition function calculations [6-8], or kinetic calculations [9-10] or even collisional-radiative models [11]. 
For all methods the question is: what is the relationship between the electron temperature $T_{e}$ and that of heavy species $T_{h}$ when the electron density varies? An approach has been proposed by André et al [12] where the ratio $\theta_{e}=T_{e} / T_{h}$ depends on $\ln \left(n_{e} / n_{e}{ }^{\max }\right)$

$$
\theta_{\mathrm{e}}=1+\mathrm{A} \cdot \ln \left(\mathrm{n}_{\mathrm{e}} / \mathbf{n}_{\mathrm{e}}^{\max }\right)
$$

$\mathrm{n}_{\mathrm{e}}{ }^{\max }$ being the electron density over which equilibrium can be assumed. The values chosen for $\mathrm{n}_{\mathrm{e}}^{\max }$ and $\mathrm{A}$ are $\mathrm{n}_{\mathrm{e}}^{\max }=10^{23} \mathrm{~m}^{-3}$ and $\mathrm{A}=-0.2$ in such a way that $\theta_{\mathrm{e}}=2$ at $5000 \mathrm{~K}$ and $\theta_{\mathrm{e}}=1.2$ at $9000 \mathrm{~K}$ in agreement with experimental values [13,14]. However, even when using the method of André et al [12] a problem is still pending when calculating the forward $\mathrm{k}_{\mathrm{f}}$ and reverse $\mathrm{k}_{\mathrm{r}}$ kinetic reaction rate coefficients. For instance, in the reaction $\mathrm{SF}^{+}+\mathrm{e} \rightarrow \mathrm{S}+\mathrm{F}$, how to keep the relationship $k_{f} / k_{r}=K_{x}$, where $K_{x}$ is the equilibrium constant, with a forward reaction linked to inelastic collisions with electrons and calculated at $T_{e}$ while the reverse reaction involves collisions between heavy species with $k_{r}$ calculated at $T_{h}$ ? To solve that problem a temperature $T^{*}$ between $T_{c}$ and $T_{h}$ has been introduced in such a way it tends towards $T_{h}$ when $n_{e}$ is low and towards $T_{e}$ when the densities of neutral species are low [15]:

$$
T^{*}=T_{e}-\left(T_{e}-T_{h}\right) \exp (-R)
$$

To fulfil these requirements $\mathrm{R}$ has been defined as the ratio of the electron flux to that of neutral species

$$
\mathrm{R}=\mathrm{n}_{\mathrm{e}} \mathrm{v}_{\mathrm{e}} / \Sigma_{\mathrm{i}} \mathrm{n}_{\mathrm{i}} \mathrm{v}_{\mathbf{i}}
$$

$v_{e}$ and $v_{i}$ being calculated easily by assuming Maxwellian distributions.

A systematic comparison of the results obtained by using the kinetic calculations and the Gibbs free energy minimization has been performed recently [15] for hydrogen and nitrogen plasmas. This study has shown that the leading reactions were those with low activation energies. The purpose of this work is to determine for a much more complex mixture such as that resulting from the heating of $\mathrm{SF}_{6}$ which are the key reactions controling the kinetics and compare the results with those of equilibrium calculations and multitemperature mass action laws calculated at $\mathrm{T}^{*}$.

\section{2-Reactions and kinetic data}

\section{2-1. General remarks}

According to the chosen method, the nonequilibrium ratio $\theta_{\mathrm{e}}$ as well as the temperature $T^{*}$, defined in eqns (1) to (3), depend strongly upon the result of the calculation through the species densities and the only mean to change them is to adjust for example the 
constants $A$ and $n_{e}{ }^{\max }$ (see eqn(1)). This method is not developed to determine precisely densities of the minor species for which the nonequilibrium effects may be drastic but to evaluate how it affects the major species on which the flow depends. As long as only the free flow calculation is considered no reactions at the wall have been taken into account.

\section{2-2. Kinetic data}

33 reactions implying 18 different species have been considered. Most of them are those proposed by Cliteur et al [5] and in table 1 are summarized only those which are not proposed by Cliteur or we have preferred. The reactions have been written as:

$$
k_{f}=A\left(T_{g, e} \text { or } T^{*}\right)^{B} \exp \left(-e \hat{C} / k\left(T_{g, e} \text { or } T^{*}\right)\right)
$$

the reverse reaction being determined by

$$
k_{r}=k_{f}\left(T_{g, e} \text { or } T^{*}\right) \cdot \Pi Z_{\text {reac }}\left(T_{g, e} \text { or } T^{*}\right) \cdot \exp \left(e \hat{E} / k\left(T_{g, c} \text { or } T^{*}\right)\right) / \Pi Z_{\text {prod }}\left(T_{g, e} \text { or } T^{*}\right)
$$

$\mathrm{Z}$ being the partition function either of the reactants or of the products, $\hat{\mathrm{C}}$ the activation energy, $\hat{E}$ the reaction energy and e the electronic charge. $\Pi$ represents the product of partition functions.

\begin{tabular}{|c|l|c|c|c|c|}
\hline Number & \multicolumn{1}{|c|}{ Reaction } & $\mathbf{A}$ & $\mathbf{B}$ & $\hat{\mathbf{C}}(\mathbf{e V})$ & $\hat{\mathbf{E}}(\mathbf{e V})$ \\
\hline 1 & $\mathrm{~F}+\mathrm{e} \rightarrow \mathrm{F}^{+}+2^{\mathrm{e}}$ & $5.010^{-7}$ & -1.500 & 17.423 & 17.423 \\
\hline 2 & $\mathrm{~F}^{+}+\mathrm{S}_{2} \rightarrow \mathrm{S}+\mathrm{S}^{+}+\mathrm{F}$ & $3.010^{-16}$ & 0 & 0 & -6.461 \\
\hline 3 & $\mathrm{~F}^{+}+\mathrm{SF} \rightarrow \mathrm{S}^{+}+2 \mathrm{~F}$ & $3.010^{-16}$ & 0 & 0 & -9.123 \\
\hline
\end{tabular}
Table 1. Considered chemical reactions different from those of Cliteur [5] for the kinetic
approach

The partition functions necessary for eqn(5) were calculated using the method proposed by Aubreton et al [7] for different temperatures.

\section{3- Results and discussion}

\section{3-1. Equilibrium calculation}

The evolution of the different species density with temperature at atmospheric pressure starting from 1 mole of $\mathrm{SF}_{6}$ is represented in fig $1 \mathrm{a}$ from 4000 to $15000 \mathrm{~K}$ and in fig $1 \mathrm{~b}$ from 1000 to $6000 \mathrm{~K}$. Over $6000 \mathrm{~K}$ practically all the species are dissociated and the main ions are $\mathrm{S}^{+}$and $\mathrm{F}^{+}$with less than $5.10^{-19} \mathrm{~m}^{-3} \mathrm{~F}^{-}$ions. Below $6000 \mathrm{~K}$ many molecules exist and the ionized species between 2700 and $3500 \mathrm{~K}$ are exclusively $\mathrm{S}_{2}{ }^{+}$and $\mathrm{F}^{-}, \mathrm{S}^{+}$and electrons starting 
to show up, at least for $n_{i}>10^{18} \mathrm{~m}^{-3}$, respectively at $3500 \mathrm{~K}$ and $3900 \mathrm{~K}$. These results are in good agreement with the published previous results [11].

SSFF and FSSF correspond to two isometric forms of $\mathrm{S}_{2} \mathrm{~F}_{2}$.
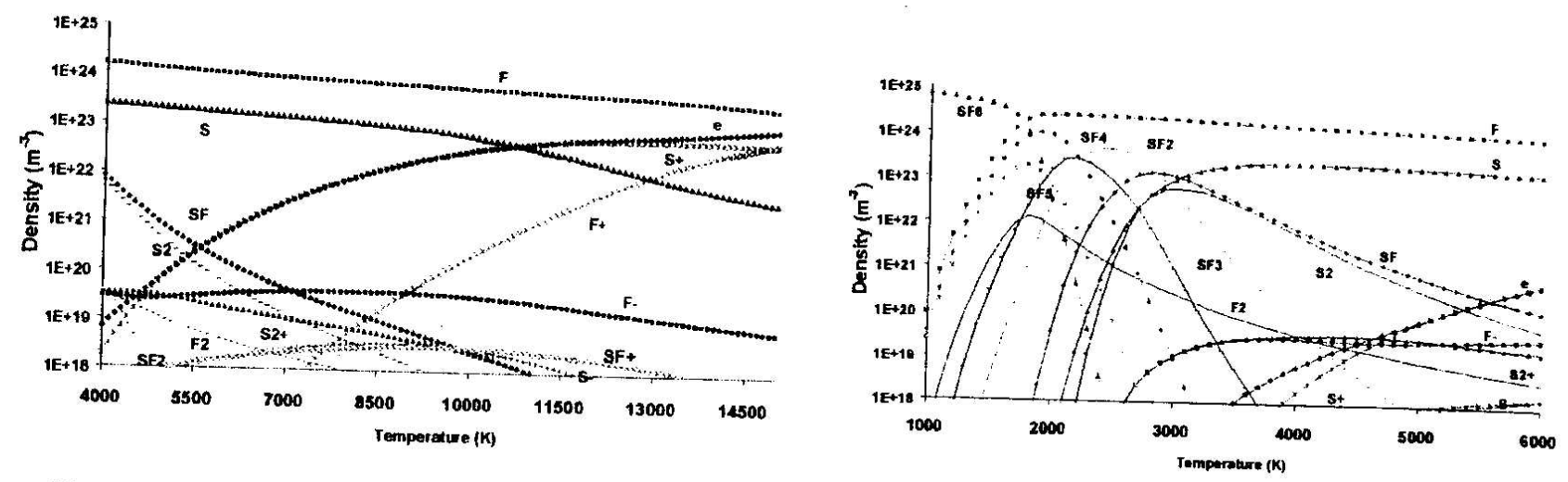

Fig 1: Equilibrium composition at atmospheric pressure of an $\mathrm{SF}_{6}$ plasma starting from 1 mole of $\mathrm{SF}_{6}$ a/ up to $15000 \mathrm{~K}$ with only diatomic molecules, atoms and ions represented, b/ up to $6000 \mathrm{~K}$.

\subsection{Multi-temperature calculation at $\mathrm{T}^{*}$}

They have been performed at $T^{*}$ (see eqns(2) and (3)) with eqn(1) allowing to determine $\theta_{\mathrm{e}}$ thanks to an iterative procedure. Fig 2 represents the variation of $\mathrm{T}_{\mathrm{e}}$ and $\mathrm{T}^{*}$ with $\mathrm{T}_{\mathrm{h}}$. Over $14000 \mathrm{~K} \theta_{\mathrm{e}} \sim 1$ and equilibrium is reached, between $6500 \mathrm{~K}$ and $14000 \mathrm{~K} \mathrm{~T}_{\mathrm{e}}$ is slightly higher than $T_{h}$ and below $5500 \mathrm{~K}$, it varies drastically with $T_{h}$. It can be noted that $T_{e}$ is very sensitive to any change in the slope of the curve $n_{e}\left(T_{e}\right)$. Correlatively $T^{*}$ is about $T_{e}$ between $6000 \mathrm{~K}$ and $14000 \mathrm{~K}$ and $\mathrm{T}_{\mathrm{h}}$ below $4000 \mathrm{~K}$. T* exhibits a strong variation between 4000 and $6000 \mathrm{~K}$.
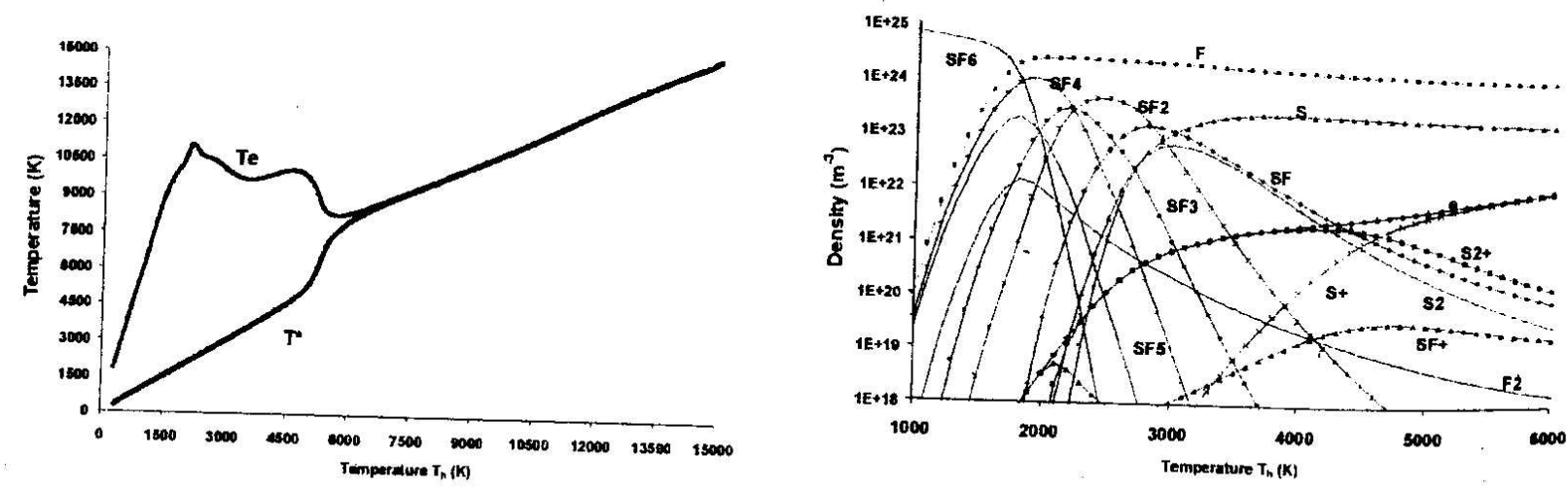

Fig 2: Evolution with heavy species temperature $T_{h}$ of the electron temperature $T_{e}$ and intermediate temperature $T^{*}$. Fig3: Evolution with heavy species temperature of the species densities calculated by using multi-temperature Gibbs free energy minimization at $T^{*}$. 
When comparing fig $1 \mathrm{~b}$ and fig 3 representing the multi-temperature composition: $\mathrm{S}^{+}$in fig 3 is between one and two orders of magnitude higher than at equilibrium and it exists over $10^{18} \mathrm{~m}^{-3}$ down to $3100 \mathrm{~K}$ against $3900 \mathrm{~K}$ at equilibrium; $\mathrm{SF}^{t}$ which did not exist at equilibrium, reachès $5.10^{19} \mathrm{~m}^{-3}$ at $5000 \mathrm{~K} ; \mathrm{S}_{2}{ }^{+}$is almost 2 orders of magnitude higher and exists down to $2000 \mathrm{~K}$ against $2600 \mathrm{~K}$ at equilibrium; $\mathrm{F}^{-}$has completely disappeared, the charge balance below $4000 \mathrm{~K}$ being made by the electrons. Beside that, the neutral species are about the same as at equilibrium. The disappearance of $\mathrm{F}^{-}$as well of $\mathrm{S}^{-}$is probably due to the exponent $1 / \theta_{e}$ in the corresponding $K_{p}$. When calculating the same composition but with no $1 / \theta_{e}$ in the $K_{p}$ of ionized species, $\mathrm{F}^{-}$and $\mathrm{S}^{-}$exist again with a value slightly higher than at equilibrium.

\subsection{Kinetic calculation}

The used method is that described in [15]. The kinetic calculations have been performed at $\mathrm{T}^{*}$.

\subsection{1.' Complete calculations}

Fig 4a represents the species densities evolution with $T_{h}$. The complex molecules FSSF and SSFF have not been taken into account due to the lack of data. Over $6000 \mathrm{~K}$, there is not much differences between both equilibrium and multi-temperature calculations. The main differences between kinetic calculations and the two other calculations show up mainly for $\mathrm{S}^{+}$, $\mathrm{S}_{2}^{+}, \mathrm{F}^{-}, \mathrm{S}^{-}$and $\mathrm{SF}^{+}$species. Compared to equilibrium $\mathrm{S}^{+}$shows up over $10^{18} \mathrm{~m}^{-3}$ at a temperature of about $100 \mathrm{~K}$ lower and its slope increases drastically over $5000 \mathrm{~K}$. The difference with equilibrium reaches more than one order of magnitude at $6000 \mathrm{~K}$. Of course over $4800 \mathrm{~K}$ all the electrons come from $\mathrm{S}$ ionization. $\mathrm{F}^{-}$starts, as at equilibrium, at $2600 \mathrm{~K}$ but over $3000 \mathrm{~K}$ it is slightly higher than at equilibrium and compensated by $\mathrm{S}_{2}{ }^{+}$. Over $3900 \mathrm{~K}$ it decreases slightly compared to $\mathrm{S}_{2}{ }^{+}$, which starts to diminish at $4700 \mathrm{~K}$ and becomes lower than $\mathrm{F}^{-}$around $5000 \mathrm{~K} ; \mathrm{S}^{-}$is higher than at equilibrium. Over $4000 \mathrm{~K}$ SF becomes smaller than at equilibrium with a change in its slope at $5200 \mathrm{~K} ; \mathrm{S}_{2}$ is also lower than at equilibrium below $4000 \mathrm{~K}$. SF ${ }^{+}$shows up at $4400 \mathrm{~K}$ (there is none at equilibrium) but it is still only $4.10^{18} \mathrm{~m}^{-3}$ at $6000 \mathrm{~K} . \mathrm{S}^{-}$and $\mathrm{F}^{+}$appear at 5300 and $5500 \mathrm{~K}$, respectively but remain below $10^{19} \mathrm{~m}^{-3}$. The rather good agreement between equilibrium and kinetic calculations is due to the fact that below $4500 \mathrm{~K} \mathrm{~T}^{*}$ is very close to $T_{h}$ and over $6500 \mathrm{~K} \mathrm{~T}^{*}$ is equal to $T_{\mathrm{e}}$ which is not very different from $T_{h}$ and tends smoothly towards $T_{h}$, the equilibrium being reached at $14000 \mathrm{~K}$. When comparing with fig 3 (multi-temperature) the differences are drastic for $\mathrm{S}^{+}, \mathrm{SF}^{+}, \mathrm{S}_{2}{ }^{+}$and F- For more details see section 3.2 . 


\subsubsection{Calculations neglecting charge loss reactions}

The kinetic calculations when neglecting the charge loss reactions are shown in fig $4 \mathrm{~b}$. As could be expected when neglecting the following reactions : $\mathrm{S}^{-}+\mathrm{S}^{+}+\mathrm{F} \rightarrow \mathrm{S}_{2}+\mathrm{F}, \mathrm{F}^{-}+\mathrm{S}^{+}+$ $\mathrm{F} \rightarrow \mathrm{SF}+\mathrm{F}, \mathrm{SF}^{+}+\mathrm{e} \rightarrow \mathrm{S}+\mathrm{F}, \mathrm{S}_{2}{ }^{+}+\mathrm{e} \rightarrow 2 \mathrm{~S}, \mathrm{~S}_{2}{ }^{+}+\mathrm{F}^{-}+\mathrm{F} \rightarrow \mathrm{S}_{2}+2 \mathrm{~F}, \mathrm{~S}_{2}{ }^{+}+\mathrm{F}^{-}+\mathrm{F} \rightarrow \mathrm{SF}+\mathrm{F}+$ $\mathrm{S}, \mathrm{S}_{2}{ }^{+}+\mathrm{F}^{-}+\mathrm{F} \rightarrow \mathrm{S}_{2}+\mathrm{F}_{2}, \mathrm{~S}_{2}{ }^{+}+\mathrm{F}^{-}+\mathrm{F} \rightarrow 2 \mathrm{SF}$, over $1500 \mathrm{~K}$ ionization is due to the formation first of $\mathrm{SF}^{+}$and then of $\mathrm{S}_{2}{ }^{+}$which are compensated exclusively by $\mathrm{F}^{-}$which reaches $8.10^{22} \mathrm{~m}^{-3}$ at $2500 \mathrm{~K}$ (very high value : $3 \%$ of the neutrals). $\mathrm{F}^{-}$is probably due to the trapping of electrons by $\mathrm{F}$ (all reactions where electrons recombine with ions being eliminated as well as the reactions of $\mathrm{F}^{-}$with ions). Electrons start to appear at $2000 \mathrm{~K}$ and increase drastically up to $2500 \mathrm{~K}$ and more slowly over that temperature while $\mathrm{F}$ decreases. Contrarily to what has been shown for $\mathrm{N}_{2}$ or $\mathrm{H}_{2}$ [15] the composition is far from that obtained with the multi-temperature method.
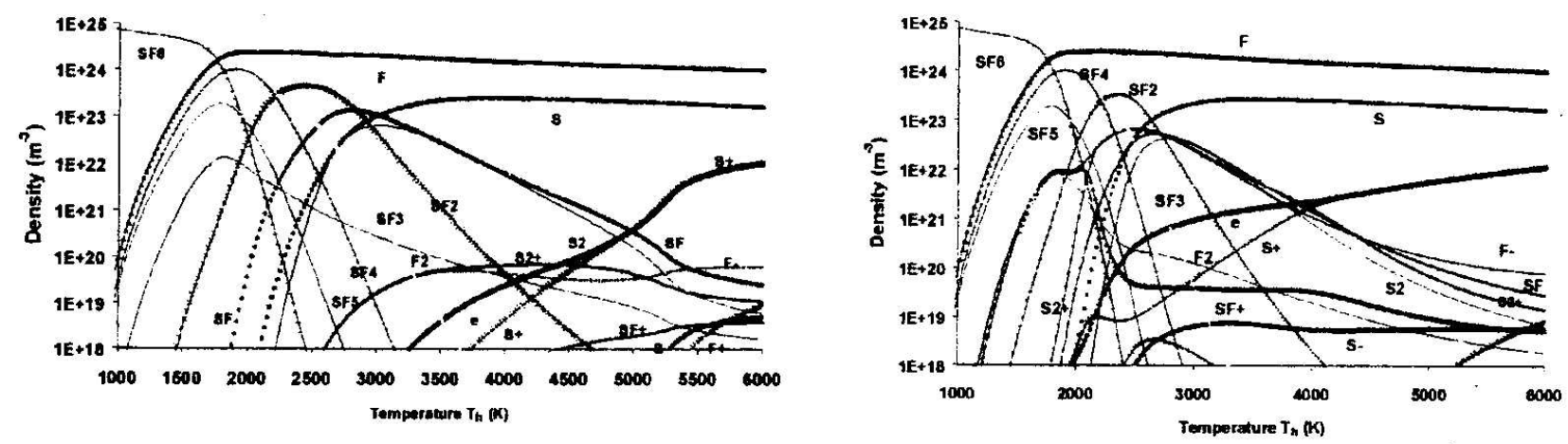

Fig 4.: Evolution with heavy species temperature $T_{h}$ of the species densities calculated a/ complete calculations, $\mathrm{b} /$ neglecting charge loss reactions.

\section{4- Conclusion}

The method developed to calculate the kinetic composition of $\mathrm{H}_{2}$ or $\mathrm{N}_{2}$ plasmas has been extended to $\mathrm{SF}_{6}$ plasmas where 33 reactions are involved instead of 7 in the two previous cases. It consists of establishing a relationship between the electron temperature $T_{e}$ and the heavy species temperature $T_{h}$. The ratio $T_{e} / T_{h}$ varies as a function of the logarithm of the ratio $n_{e} / n_{e}{ }^{\max }, n_{e}{ }^{\max }$ being the electron density in the plasma core for which equilibrium is established $\left(\mathrm{n}_{\mathrm{e}}^{\text {max }} \sim 10^{23} \mathrm{~m}^{-3}\right)$. The kinetic calculations have been performed by assuming the microreversibility between the backward and forward kinetic coefficients using a temperature $T^{*}$ between $T_{e}$ and $T_{h}$ determined as a function of the ratio of electron flux to that of neutral 
species. Contrarily to what happens with $\mathrm{N}_{2}$ and $\mathrm{H}_{2}$ plasma, where the main differences between equilibrium and kinetic calculations occur between 1500 and $9000 \mathrm{~K}$, with $\mathrm{SF}_{6}$ the main differences show up between 1500 and $6000 \mathrm{~K}$ and are related to the populations of $\mathrm{S}^{+}$, $\mathrm{S}_{2}^{+}, \mathrm{SF}^{+}, \mathrm{F}^{-}$and $\mathrm{S}^{+}$species.

\section{$\underline{\text { References }}$}

[1] Potapov A.V., High Temp., vol 4, 1966, pp48-51.

[2] Van de Sanden M.C.M., Schram P.P.J.M., Peeters A.G., Van der Mullen J.A.M., and Kroesen G.M.W., Physical Review A, vol 40, no9, 1989, pp5273-5276.

[3] Gleizes A., Chervy B. and Gonzalez J.J., J. Phys.D : Appl. Phys. vol 32, 1999, pp20602067.

[4] Tanaka Y., Yokomizu Y, Ishikawa M and Matsumura T. IEEE Trans. Plasma Sci. vol 25, 1997, pp991.

[5] Cliteur G.J., Suzuki K., Tanaka Y., Sakuta T., Matsubara T., Yokomizu Y. and Matsumura T, J. Phys.D : Appl. Phys. vol 32, 1999, pp1851-1856.

[6] P. André, Abbaoui M., Lefort A. and Parizet M.J., Plasma Chem. and Plasma Proc., vol 16, no3, 1996, pp379-398.

[7] Aubreton J, Elchinger M.F. and Fauchais P., Plasma Chem. Plasma Proc. vol 18 no1, 1998, pp262-283.

[8] Combadière S., Aubreton J., Elchinger M.F., and Fauchais P., in Progress in Plasma Processing of Materials, (Ed.) P. Fauchais and J. Amouroux, (Pub.) Begell House, Inc. New York., 1998 , pp473-480.

[9] Richley E., Tuma D.T., J. Appl. Phys. vol 3, no12, 1982, pp8537-8341.

[10] Kee R.J., Rupley F.M., Miller J.A. A fortran chemical kinetics package for the analysis of gas-phase chemical kinetics. Sandia National Laboratories Report SAND89-8009, 1989.

[11] Sarrette J.Ph., Gomes A.M. and Bacri J., Proc. of the Int. Symp. on Heat and Mass Transfer under Plasma Conditions, (edt.) P. fauchais, (Pub.) Begell house, 1994, pp119-126.

[12] André P., Aubreton J., Elchinger M.F., Fauchais P., and Lefort A., (eds.) P. Fauchais, J. Amouroux (Pub.) The Annals of the New York Academy of Sciences, 1999, pp85-94.

[13] Fauchais, P. Coudert J.F., M. Vardelle . In Plasma Diagnostics (eds.) D. Flamm and F. Aucellio (Pub.) Academic Press Inc. NY, USA, vol 1, 1989, pp349-446. 
[14] Gordon M.H. and Kruger C.H., Plasma Chemistry and Plasma Processing, vol 13, no3, 1993, pp365-378.

[15] André P., Aubreton J., Elchinger M.F., Fauchais P. and Lefort A., " A new modified pseudo-equilibrium calculation to determine the composition of hydrogen and nitrogen plasmas at atmospheric presssure ", accepted in Plasma Chemistry and Plasma Processing [16] Gleizes A., Razafinimanana M., Vacquié S., in Proc. of $7^{\text {th }}$ int. Symp. on Plasma Chem. (ed.) Timmermans (Pub.) Univ. of Techno. of Eindhoven, vol 1, 1985, pp842-847. 